\title{
Protective benefit of predominant breastfeeding against otitis media may be limited to early childhood: results from a prospective birth cohort study
}

Christopher G. Brennan-Jones ${ }^{\text {a b }}$

Robert H. Eikelboom ${ }^{\text {ab }}$

Angela Jacques ${ }^{\mathrm{de}}$

De Wet Swanepoel ${ }^{\text {abc }}$

Marcus D. Atlas ${ }^{a b}$

Andrew J.O. Whitehouse ${ }^{\mathrm{d}}$

Sarra E. Jamieson ${ }^{\mathrm{d}}$

Wendy H. Oddy ${ }^{\text {d }}$

a) Ear Science Institute Australia, Subiaco, Subiaco, Australia

b) Ear Sciences Centre, School of Surgery, The University of Western Australia, Crawley, Australia

c) Department of Speech-Language Pathology and Audiology, University of Pretoria, South Africa

d) Telethon Kids Institute, The University of Western Australia, Crawley, Australia

e) School of Population Health, The University of Western Australia, Crawley, Australia

\section{LIST OF ABBREVIATIONS}

AOM: Acute otitis media

OM: Otitis media

OME: Otitis media with effusion

OR: Odds ratio

CI: $95 \%$ confidence interval

\section{CONTACT AUTHOR}

Christopher G. Brennan-Jones

Ear Science Institute Australia

Suite 1, Level 2, 1 Salvado Road, SUBIACO WA 6008

P 0863804900 |F 0863804901

\section{What is known about this topic:}

- The positive benefits of breastfeeding for children are widely recognised

- The effect of predominant breastfeeding on the incidence of otitis media is still unclear

- Previous cohort studies have followed up these outcomes in infants for a relatively short period of time (usually 6 to 24 months of age) 
Brennan-Jones et al.

\title{
What this study adds:
}

- This study shows that a significant, protective association $(p=0.01)$ between breastfeeding and incidence of $\mathrm{OM}$ at 3 years of age, but not at six years of age in a longitudinally-studied cohort.

- The protective profile of breastfeeding for otitis media may not extend beyond early childhood.

\begin{abstract}
Objectives: To examine the long-term effects of predominant breastfeeding on incidence of otitis media.

Design: Prospective birth cohort study.

Setting: The West Australian Pregnancy Cohort (Raine) Study recruited 2900 mothers through antenatal clinics at the major tertiary obstetric hospital in Perth, Western Australia between 1989 and 1992.
\end{abstract}

Participants: 2237 children participated in a six year cohort follow-up and a subset of 1344 were given ear and hearing assessments.

Main outcome measures: OM diagnosis at six years of age (diagnosed by low-compliance tympanograms, $0-0.1 \mathrm{mmho}$ ). This was compared to OM diagnosed at the three year cohort follow-up using parent-report measures. Main exposure measures were duration of predominant breastfeeding (defined as the age other milk was introduced) and duration of partial (any) breastfeeding (defined as the age breastfeeding was stopped).

Results: There was a significant, independent association between predominant breastfeeding $(\mathrm{OR}=1.33[1.04,1.69] ; p=0.02)$ and $\mathrm{OM}$, and breastfeeding duration $(\mathrm{OR}=1.35[1.08$, $1.68] ; p=0.01$ ) with $\mathrm{OM}$ at three years of age. However, at six years of age this relationship 
Brennan-Jones et al.

was no longer statistically significant (predominant breastfeeding $\mathrm{OR}=0.78[0.48,1.06] ; p=$ 0.09; duration of breastfeeding, $\mathrm{OR}=1.34[0.81,2.23] ; p=0.25)$.

Conclusions: Our findings are in line with a number of epidemiological studies which show a positive association between breastfeeding and OM in early childhood. However, the longterm follow-up of these children revealed that by six years of age there was no significant influence of breastfeeding on presence of OM. These results suggest that the protective effect of predominant breastfeeding for at least six months does not extend to school-age children, where other social and environmental factors may be stronger predictors of OM.

\section{KEYWORDS}

Otitis media; glue ear; epidemiology; Raine Study; breastfeeding; Western Australia

\section{INTRODUCTION}

Otitis media (OM), is a one of the most common diseases in childhood and is estimated to affect over $90 \%$ of children before their second birthday. ${ }^{1}$ It is also the highest cause of antimicrobial prescriptions ${ }^{2}$ and surgery in children. ${ }^{3}$ The clinical course of OM and its sequelae are varied; some children will experience a spontaneous resolution of symptoms with no lasting effects, whilst others will receive medication, with or without surgical intervention, which is often effective in resolving or stopping the progression of the disease. ${ }^{4,5}$ Unfortunately many children will experience recurrent and more severe episodes of the OM with extended periods of middle ear effusion that are associated with decreased hearing sensitivity. Middle ear effusion as a result of OM can occur due to acute episodes and

typically lasts between one to four weeks, ${ }^{6}$ with episodes lasting for greater than three months are generally considered chronic. ${ }^{7}$ Whilst the potential for poorer developmental outcomes for children with permanent hearing losses are well established, ${ }^{8-10}$ the lasting effects on 
Brennan-Jones et al.

developmental outcomes due to the temporary hearing loss associated with middle ear effusion due to OM are less clear, although they are proposed to result in language, behavioural and other developmental problems, as well as poorer educational achievement. ${ }^{10-}$ 13

Previous research has primarily examined the association between breastfeeding and OM incidence in infancy, with few study cohorts following children long enough to examine if there is a lasting relationship between breastfeeding and OM that persists into early childhood. This study aimed to address this question by examining the relationship between predominant breastfeeding and duration of any breastfeeding with the presence of OM at three and six years of age, whilst accounting for known covariates. Data from an established pregnancy cohort were used for this study.

\section{METHODS}

\section{Cohort setting}

The Western Australian Pregnancy Cohort (Raine) Study is a pregnancy cohort consisting of 2868 children born between 1989 and $1992 .{ }^{14}$ The Raine Study enrolled pregnant women at 16 to 20 weeks gestation from King Edward Memorial Hospital, the major tertiary maternity hospital in Perth, Western Australia, along with nearby private medical centres.

\section{Cohort recruitment}

Mothers were selected for enrolment if they had sufficient proficiency in English, expected to deliver at the hospital, and intended to remain in Western Australia for child follow-up into adulthood $^{31}$. 
Brennan-Jones et al.

\section{Predictor variables}

Breastfeeding data were measured in two ways. Data on any and predominant breastfeeding were collated from feeding questionnaires completed by mothers at the 1,2 and 3 year follow-ups. Any breastfeeding was measured as the age breastfeeding stopped. Predominant breastfeeding was presumed to occur up until the introduction of milk other than breast milk and was considered a proxy measurement of exclusive breastfeeding. The predictor variables were coded into categorical variables of breastfeeding duration less than six months compared to six months or longer, and the introduction of other milk at less than six months of life (not including the intake of solid foods), compared to introduction at six months or later, as determined by the parental feeding questionnaires.

\section{Outcome variable}

The main outcome variable was the presence of $\mathrm{OM}$ at six years of age. The identification of a broad diagnosis of OM (which could be either acute otitis media or otitis media with effusion) in the cohort was assessed by otoscopic examination with tympanometry at six years of age. Children were considered exposed to OM if tympanometry showed bilateral "Type B" low compliance $(0-0.1 \mathrm{mmho})$ tympanograms at six years of age. The presence of $\mathrm{OM}$ at three years of age was used as a secondary outcome variable. At three years of age parents of children included in study were asked the yes/no question "Has your child ever in his/her life [had] otitis media (middle ear infection)? If so, how many?". The parental report of three or more episodes of OM in the first three years of life constituted a diagnosis of OM in the cohort. Clinical examinations were performed by a specialist nurse and children were also considered to have OM if, at either of the first-year, second-year or third-year followups, clinical examination with otoscopy revealed any of the following: presence of scarred, retracted, inflamed or perforated tympanic membranes, the presence of middle ear effusion or ventilation-tubes (i.e. grommets) in situ. Due to the broad nature of the classification of OM 
Brennan-Jones et al.

in the cohort at three years of age, we were unable to determine the specific clinical features for individual participants.

\section{Covariates}

A number of covariates in the study cohort that have previously been shown ${ }^{15,16}$ or hypothesised to influence either OM or breastfeeding practices ${ }^{17}$ were available in the Raine Study database and were included in the multivariate analysis. These included maternal education (completed high school), maternal language, maternal ethnicity, maternal alcohol consumption during pregnancy, below average household income $(<\$ 24 \mathrm{k})$, sex of the child, parity, birth weight (low birth weight $<2500$ g), prematurity (gestational age <37 weeks), exposure to passive smoking and day care attendance.

\section{Cohort assessment and follow-up}

The Raine Study used both medical records and parental self-report measures to collect detailed demographic and medical data prenatally and at birth. Parents were asked to keep detailed diaries of their child's medical history. During follow-up visits, parents completed questionnaires describing any illnesses and medical problems, which were coded by Raine

Study research staff using International Classification of Diseases, 9 th Revision. ${ }^{18}$ Informed consent was obtained for follow up of the children from birth.

\section{Eligibility of participants for present study: Inclusion criteria}

All women and their children who were eligible to participate in the Raine Study were eligible for inclusion in this study.

\section{Eligibility of participants for present study: Exclusion criteria}

Children with missing OM or breastfeeding data were excluded casewise from the study. 
Brennan-Jones et al.

\section{Ethics declaration}

Participant recruitment and follow-up for the Raine Study was approved by human ethics committees at the main maternity unit at King Edward Memorial Hospital and paediatric unit at Princess Margaret Hospital, in Perth, Western Australia. Parents provided written informed consent and participants were re-consented at 18 years of age for the use of stored data.

Approval for the release of data for this project has been given by the Raine Study Executive Committee through approval of a project proposal.

\section{Statistical analysis methods}

Frequencies for predictor and outcome variables were summarised in relation to presence or absence of OM. Multivariable regression analysis to examine the effect of the categorical breastfeeding predictor variables and covariates on OM status at three and six years of age was conducted using a binary logistic model. All statistical analyses were undertaken using SPSS software version 21.0 (New York: IBM Corp.).

\section{RESULTS}

Otitis media assessment data were obtained for a subset of 1344 children at the six year follow-up and were classified as having OM or not $(n=143)$. Of these, 1283 had complete data relating to the introduction of other milk (i.e. predominant breastfeeding) and 1276 had complete data relating to breastfeeding duration (Table 1). The mean age of participants at follow-up was 5.91 (SD 0.22) years, with ages ranging from 5.08 to 7.25 years. At the three year follow-up a subset of 2280 children were examined; of these 2105 had complete data relating to the breastfeeding variables and 577 children were classified as having OM based on parental-report, clinical examination or both (Table 1). Of the 143 children with OM at the six year follow-up, 42 of these children (29.4\%) also had an OM diagnosis at three years of 
Brennan-Jones et al.

Table 1: Frequency distribution of bilateral $\mathrm{OM}$ at six years and parent-report of $\mathrm{OM}$ at three years of age and breastfeeding in infancy from the West Australian Pregnancy Cohort (Raine) Study

\begin{tabular}{|c|c|c|c|c|c|c|c|}
\hline \multicolumn{2}{|c|}{ Breastfeeding variable } & \multicolumn{2}{|c|}{ OM at 6 years } & $\left(\mathrm{X}^{2}\right) p^{*}$ & \multicolumn{2}{|c|}{ OM at 3 years } & $\left(X^{2}\right) p^{*}$ \\
\hline & & No (\%) & Yes (\%) & & No (\%) & Yes (\%) & - \\
\hline \multirow{4}{*}{$\begin{array}{l}\text { Other milk } \\
\text { introduced <6mo }\end{array}$} & No & $324(86.6)$ & $50(13.3)$ & - & $441(75.6)$ & $142(24.4)$ & - \\
\hline & Yes & $809(89.7)$ & $93(10.3)$ & 0.115 & $1087(71.4)$ & $435(28.6)$ & 0.056 \\
\hline & Subtotal & $1133(88.8)$ & $143(11.2)$ & & $1528(72.6)$ & $577(27.4)$ & - \\
\hline & Missing & $56(4.1)$ & $12(0.9)$ & - & $172(7.5)$ & 0 & - \\
\hline \multirow{4}{*}{$\begin{array}{l}\text { Breastfeeding } \\
\text { stopped at }<6 \text { mo }\end{array}$} & No & $633(88.2)$ & $85(11.8)$ & - & $837(74.0)$ & $294(26.0)$ & - \\
\hline & Yes & $507(89.7)$ & $58(10.3)$ & 0.375 & $702(71.1)$ & $285(28.9)$ & 0.138 \\
\hline & Subtotal & $1140(88.9)$ & $143(11.1)$ & & $1539(72.7)$ & $579(27.3)$ & - \\
\hline & Missing & $49(3.6)$ & $12(0.9)$ & - & $159(7.0)$ & 0 & - \\
\hline
\end{tabular}

* $\mathrm{X}^{2}$ comparisons for gender 
Brennan-Jones et al.

Table 2: Frequency distributions of covariates related to OM in the Raine Study cohort

\begin{tabular}{|c|c|c|c|c|}
\hline \multirow[b]{2}{*}{ Covariates } & \multicolumn{4}{|c|}{ OM at six years } \\
\hline & \multicolumn{2}{|r|}{ No $(\%)$} & Yes (\%) & $\left(\mathrm{X}^{2}\right) p$ \\
\hline \multirow{2}{*}{$\begin{array}{l}\text { Maternal education: Did mum } \\
\text { finish year } 12\end{array}$} & No & $660(49.9)$ & $77(5.8)$ & 0.207 \\
\hline & Yes & $510(38.6)$ & $74(5.6)$ & reference \\
\hline \multirow[t]{2}{*}{ Maternal language } & English & $1132(84.2)$ & $139(10.3)$ & reference \\
\hline & Other & $57(4.2)$ & $16(1.2)$ & 0.004 \\
\hline \multirow[t]{2}{*}{ Maternal ethnicity } & Caucasian & $1085(80.7)$ & $133(9.9)$ & reference \\
\hline & Other & $104(7.7)$ & $22(1.6)$ & 0.029 \\
\hline \multirow{2}{*}{$\begin{array}{l}\text { Consumed alcohol during } \\
\text { pregnancy (<34 weeks) }\end{array}$} & No & $657(52.5)$ & $88(7.0)$ & reference \\
\hline & Yes & $450(36.0)$ & $55(4.4)$ & 0.616 \\
\hline \multirow{2}{*}{$\begin{array}{l}\text { Household income less than } \\
\$ 24 \mathrm{~K} \text { (poverty line) }\end{array}$} & No & 709 (55.3) & $88(6.7)$ & reference \\
\hline & Yes & $425(33.1)$ & $60(4.7)$ & 0.470 \\
\hline \multirow[t]{2}{*}{ Offspring SEX } & Female & $553(41.1)$ & $84(6.2)$ & reference \\
\hline & Male & 636 (47.3) & $71(5.3)$ & 0.072 \\
\hline \multirow[t]{2}{*}{ Parity } & No siblings & 528 (39.3) & $69(5.1)$ & reference \\
\hline & One or more & 661 (49.2) & $85(6.3)$ & 0.925 \\
\hline \multirow{2}{*}{$\begin{array}{l}\text { Offspring weight at birth } \\
<2500 \mathrm{~g}\end{array}$} & No & 1103 (82.2) & $142(10.6)$ & reference \\
\hline & Yes & $83(6.2)$ & $13(1.0)$ & 0.528 \\
\hline \multirow{2}{*}{$\begin{array}{l}\text { Offspring gestational age at } \\
\text { birth }<37 \text { weeks }\end{array}$} & No & $1086(82.5)$ & $139(10.6)$ & reference \\
\hline & Yes & $79(6.0)$ & $12(1.0)$ & 0.595 \\
\hline \multirow{2}{*}{$\begin{array}{l}\text { Passive smoking exposure } \\
\text { (years 1-3) }\end{array}$} & No & $646(56.6)$ & $76(6.6)$ & reference \\
\hline & Yes & 369 (32.3) & $51(4.4)$ & 0.402 \\
\hline \multirow[t]{2}{*}{ Attended daycare (yrs 1-3) } & No & $248(26.5)$ & $42(4.5)$ & reference \\
\hline & Yes & $579(61.9)$ & $67(7.1)$ & 0.070 \\
\hline
\end{tabular}


Brennan-Jones et al.

age. Cohort characteristics for the primary outcome variable at six years and covariates included in the multivariate analysis are described in Table 2.

\section{Effect of breastfeeding duration on $O M$}

The frequency characteristics of the cohort who had breastfeeding duration data and OM status data at three $(n=2118)$ and six years $(n=1283)$ of age are presented in Table 1 . At three years of age there was a significant association between breastfeeding duration $<6$ months and $\mathrm{OM}(\mathrm{OR}=1.35[1.08,1.68] ; p=0.01)$ once adjusted for covariates, indicating a protective effect of breastfeeding for longer than 6 months (Table 3). However, at six years, Table 1 shows that $4.5 \%$ of children who had a breastfeeding duration of $<6$ months were diagnosed as having OM. This is compared to $6.6 \%$ for children who were breastfed for at least six months; this difference was not significant $\left(\mathrm{X}^{2}=0.790 ; p=0.375\right)$. A multivariate binary logistic regression model (Table 5) also showed no significant association between duration of breastfeeding and $\mathrm{OM}$ at age six years $(\mathrm{OR}=1.34[0.81,2.23] ; p=0.25)$ once adjusted for a range of sociodemographic and environmental covariates.

\section{Effect of non-exclusive breastfeeding on OM}

The characteristics of the cohort who had data relating to the introduction of milk other than breast milk at $<6$ months of age and OM status data at three and six years of age are presented in Table 1. At three years of age there was a significant association between the introduction of other milk and $\mathrm{OM}(\mathrm{OR}=1.33[1.04,1.69] ; p=0.02)$ once adjusted for covariates, indicating a protective effect for predominant breastfeeding for $\geq 6$ months (Table 4). However, at six years of age, Table 1 shows $10.3 \%$ of children who had milk other than breast milk introduced at $<6$ months were diagnosed as having OM. This is compared to an OM rate of $13.3 \%$ for children who were predominately breastfed for at least six months; this difference was not significant $\left(\mathrm{X}^{2}=2.485 ; p=0.375\right)$. When a multivariate binary logistic regression model was applied, there was also no significant association between the 
Table 3: Binary logistic multiple regression model showing associations between the breastfeeding duration $(<6 \mathrm{mo})$ and $\mathrm{OM}$ at three years of age, once adjusted for a range of covariates.

\begin{tabular}{|c|c|c|c|c|c|c|c|c|}
\hline \multicolumn{9}{|c|}{ Breastfeeding (duration $<6$ months) and other covariates for OM at 3 years } \\
\hline & \multicolumn{4}{|c|}{ Univariate analysis } & \multicolumn{4}{|c|}{ Multivariate analysis } \\
\hline & \multirow[t]{2}{*}{$p$} & \multirow{2}{*}{$\begin{array}{c}\text { OR } \\
\operatorname{Exp}(B)\end{array}$} & \multicolumn{2}{|c|}{$95 \% \mathrm{Cl}$ for OR } & \multirow[t]{2}{*}{$p$} & \multirow{2}{*}{$\begin{array}{c}\text { OR } \\
\operatorname{Exp}(B)\end{array}$} & \multicolumn{2}{|c|}{$95 \% \mathrm{Cl}$ for OR } \\
\hline & & & Lower & Upper & & & Lower & Upper \\
\hline Breastfeeding duration $(<6 \mathrm{mo})$ & .136 & 1.156 & .955 & 1.400 & $.009^{*}$ & 1.346 & 1.078 & 1.680 \\
\hline High maternal education (Y12+) & .837 & .980 & .811 & 1.185 & .734 & 1.041 & .826 & 1.312 \\
\hline Multilingual mother & $.038^{\star}$ & .613 & 0.386 & 0.973 & .737 & .899 & .481 & 1.677 \\
\hline Maternal ethnicity: Caucasian & $<.001^{*}$ & .319 & 0.290 & 0.484 & $<.001^{*}$ & .373 & .225 & .618 \\
\hline Alcohol consumed in pregnancy & .005 & 1.321 & 1.087 & 1.605 & .137 & 1.180 & .949 & 1.468 \\
\hline Low household income $(<\$ 24 k)$ & .484 & .933 & .768 & 1.133 & .553 & 1.072 & .852 & 1.349 \\
\hline Sex: male & .101 & 1.168 & .970 & 1.407 & .152 & 1.168 & .945 & 1.444 \\
\hline Parity: $\geq 1$ sibling & $<.001$ & 1.398 & 1.160 & 1.686 & $<.001^{\star}$ & 1.497 & 1.204 & 1.862 \\
\hline Low birth weight $(<2500 \mathrm{~g})$ & .550 & .901 & .641 & 1.267 & .469 & .792 & .421 & 1.489 \\
\hline Premature (<37 weeks) & .478 & .883 & .626 & 1.245 & .872 & .951 & .518 & 1.747 \\
\hline Passive smoking exposure (0-3 yrs) & .553 & 1.061 & .873 & 1.289 & .950 & .992 & .778 & 1.265 \\
\hline Attended day care (0-3 yrs) & $<.001$ & 1.819 & 1.461 & 2.263 & $<.001^{\star}$ & 2.024 & 1.562 & 2.621 \\
\hline
\end{tabular}


Brennan-Jones et al.

Table 4: Binary logistic multiple regression model showing associations between the introduction of other milk $(<6 \mathrm{mo})$ and $\mathrm{OM}$ at three years of age, once adjusted for a range of covariates.

\begin{tabular}{|c|c|c|c|c|c|c|c|c|}
\hline \multicolumn{9}{|c|}{ Breastfeeding (other milk introduced $<6$ months) anc } \\
\hline 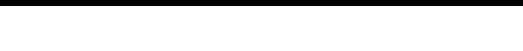 & \multicolumn{4}{|c|}{ Univariate analysis } & \multicolumn{4}{|c|}{ Multivariate analysis } \\
\hline & \multirow[t]{2}{*}{$p$} & \multirow{2}{*}{$\begin{array}{c}\mathrm{OR} \\
\mathrm{Exp}(\mathrm{B})\end{array}$} & \multicolumn{2}{|c|}{$95 \% \mathrm{Cl}$ for OR } & \multirow[t]{2}{*}{$p$} & \multirow{2}{*}{$\begin{array}{c}\text { OR } \\
\text { Exp(B) }\end{array}$} & \multicolumn{2}{|c|}{$95 \% \mathrm{Cl}$ for OR } \\
\hline & & & Lower & Upper & & & Lower & Upper \\
\hline Other milk introduced $(<6 \mathrm{mo})$ & .052 & 1.243 & .998 & 1.548 & $.024^{\star}$ & 1.326 & 1.039 & 1.694 \\
\hline High maternal education (Y12+) & .837 & .980 & .811 & 1.185 & .600 & 1.064 & .845 & 1.338 \\
\hline Multilingual mother & $.038^{\star}$ & .613 & 0.386 & 0.973 & .743 & .901 & .483 & 1.681 \\
\hline Maternal ethnicity: Caucasian & $<.001^{*}$ & .319 & 0.290 & 0.484 & $<.001^{*}$ & .374 & .226 & .618 \\
\hline Alcohol consumed in pregnancy & .005 & 1.321 & 1.087 & 1.605 & .171 & 1.165 & .936 & 1.449 \\
\hline Low household income $(<\$ 24 \mathrm{k})$ & .484 & .933 & .768 & 1.133 & .482 & 1.086 & .863 & 1.366 \\
\hline Sex: male & .101 & 1.168 & .970 & 1.407 & .128 & 1.180 & .954 & 1.459 \\
\hline Parity: $\geq 1$ sibling & $<.001$ & 1.398 & 1.160 & 1.686 & $<.001^{*}$ & 1.476 & 1.187 & 1.835 \\
\hline Low birth weight $(<2500 \mathrm{~g})$ & .550 & .901 & .641 & 1.267 & .446 & .782 & .415 & 1.472 \\
\hline Premature (<37 weeks) & .478 & .883 & .626 & 1.245 & .734 & .900 & .490 & 1.654 \\
\hline Passive smoking exposure (0-3 yrs) & .553 & 1.061 & .873 & 1.289 & .985 & 1.002 & .787 & 1.276 \\
\hline Attended day care (0-3 yrs) & $<.001$ & 1.819 & 1.461 & 2.263 & $<.001^{*}$ & 1.991 & 1.536 & 2.579 \\
\hline
\end{tabular}


Table 5: Binary logistic multiple regression model showing associations between duration of breastfeeding $(<6 \mathrm{mo})$ and $\mathrm{OM}$ at six years of age, once adjusted for a range of covariates.

\begin{tabular}{|c|c|c|c|c|c|c|c|c|}
\hline \multicolumn{9}{|c|}{ Breastfeeding duration and other covariates for OM } \\
\hline & \multicolumn{4}{|c|}{ Univariate analysis } & \multicolumn{4}{|c|}{ Multivariate analysis } \\
\hline & \multirow[t]{2}{*}{$p$} & \multirow{2}{*}{$\begin{array}{c}\text { OR } \\
\text { Exp(B) }\end{array}$} & \multicolumn{2}{|c|}{$95 \% \mathrm{Cl}$ for $\mathrm{OR}$} & \multirow[t]{2}{*}{$p$} & \multirow{2}{*}{$\begin{array}{c}\text { OR } \\
\text { Exp(B) }\end{array}$} & \multicolumn{2}{|c|}{$95 \% \mathrm{Cl}$ for OR } \\
\hline & & & Lower & Upper & & & Lower & Upper \\
\hline Breastfeeding duration $(<6 \mathrm{mo})$ & .374 & .852 & .598 & 1.213 & .255 & 1.342 & .809 & 2.227 \\
\hline High maternal education (Y12+) & .208 & .804 & .573 & 1.129 & .235 & .732 & .438 & 1.225 \\
\hline Multilingual mother & $.005^{\star}$ & 2.286 & 1.278 & 4.090 & .435 & 1.463 & .563 & 3.799 \\
\hline Maternal ethnicity: Caucasian & $.030^{\star}$ & 1.726 & 1.053 & 2.828 & .136 & 1.817 & .829 & 3.980 \\
\hline Alcohol consumed in pregnancy & .616 & 1.096 & .766 & 1.567 & .718 & 1.099 & .660 & 1.828 \\
\hline Low household income $(<\$ 24 k)$ & .470 & .879 & .620 & 1.247 & .371 & .792 & .476 & 1.320 \\
\hline Sex: male & .072 & 1.361 & .972 & 1.904 & $.031^{*}$ & 1.697 & 1.048 & 2.746 \\
\hline Parity: $\geq 1$ sibling & .925 & 1.016 & .725 & 1.424 & .752 & .924 & .568 & 1.504 \\
\hline Low birth weight $(<2500 \mathrm{~g})$ & .529 & .822 & .447 & 1.513 & .962 & 1.031 & .302 & 3.523 \\
\hline Premature $(<37$ weeks $)$ & .596 & .843 & .448 & 1.586 & .205 & .441 & .124 & 1.564 \\
\hline Passive smoking exposure (0-3 yrs) & .402 & .851 & .584 & 1.241 & .255 & .727 & .420 & 1.259 \\
\hline Attended day care (0-3 yrs) & .071 & 1.464 & .968 & 2.213 & $.041^{\star}$ & 1.677 & 1.022 & 2.750 \\
\hline
\end{tabular}


Brennan-Jones et al.

Table 6: Binary logistic multiple regression model showing associations between the introduction of other milk $(<6 \mathrm{mo})$ and $\mathrm{OM}$ at six years of age, once adjusted for a range of covariates.

\begin{tabular}{|c|c|c|c|c|c|c|c|c|}
\hline & \multicolumn{4}{|c|}{ Univariate analysis } & \multicolumn{4}{|c|}{ Multivariate analysis } \\
\hline & \multirow[t]{2}{*}{$p$} & \multirow{2}{*}{$\begin{array}{c}\text { OR } \\
\operatorname{Exp}(B)\end{array}$} & \multicolumn{2}{|c|}{$95 \% \mathrm{Cl}$ for OR } & \multirow[t]{2}{*}{$p$} & \multirow{2}{*}{$\begin{array}{c}\text { OR } \\
\operatorname{Exp}(B)\end{array}$} & \multicolumn{2}{|c|}{$95 \% \mathrm{Cl}$ for OR } \\
\hline & & & Lower & Upper & & & Lower & Upper \\
\hline Other milk introduced (<6 mo) & .116 & .745 & .516 & 1.075 & .091 & .708 & .475 & 1.056 \\
\hline High maternal education (Y12+) & .208 & .804 & .573 & 1.129 & .257 & .743 & .444 & 1.242 \\
\hline Multilingual mother & $.005^{\star}$ & 2.286 & 1.278 & 4.090 & .359 & 1.567 & .600 & 4.094 \\
\hline Maternal ethnicity: Caucasian & $.030^{\star}$ & 1.726 & 1.053 & 2.828 & .108 & 1.910 & .868 & 4.206 \\
\hline Alcohol consumed in pregnancy & .616 & 1.096 & .766 & 1.567 & .856 & 1.049 & .628 & 1.750 \\
\hline Low household income $(<\$ 24 k)$ & .470 & .879 & .620 & 1.247 & .326 & .774 & .465 & 1.289 \\
\hline Sex: male & .072 & 1.361 & .972 & 1.904 & $.023^{\star}$ & 1.757 & 1.082 & 2.851 \\
\hline Parity: $\geq 1$ sibling & .925 & 1.016 & .725 & 1.424 & .699 & .908 & .557 & 1.481 \\
\hline Low birth weight $(<2500 \mathrm{~g})$ & .529 & .822 & .447 & 1.513 & .995 & .996 & .292 & 3.395 \\
\hline Premature (<37 weeks) & .596 & .843 & .448 & 1.586 & .187 & .427 & .121 & 1.511 \\
\hline Passive smoking exposure (0-3 yrs) & .402 & .851 & .584 & 1.241 & .190 & .694 & .401 & 1.199 \\
\hline Attended day care (0-3 yrs) & .071 & 1.464 & .968 & 2.213 & .062 & 1.609 & .977 & 2.648 \\
\hline
\end{tabular}

*significant at $p<0.05$ 
Brennan-Jones et al.

introduction of other milk at $<6$ months of age and presence of $\mathrm{OM}(\mathrm{OR}=0.71[0.47,1.05]$; $p=0.09)$, indicating no protective response at this age (Table 6).

\section{DISCUSSION}

Otitis media is a multifactorial disease with a range of prenatal, postnatal, genetic, social and environmental factors that contribute to its prevalence, incidence and severity. ${ }^{15,16,19} \mathrm{We}$ examined the role of predominant or any breastfeeding with the risk of OM in early childhood. We found a significant association between predominant breastfeeding and duration of breastfeeding at three years of age with parent-reported OM, but the association between breastfeeding and OM was not significant at six years of age using tympanometry for diagnosis. This indicates that the protective profile of breastfeeding may not extend beyond early childhood. However, if the critical period of language development is said to occur in the first three years of life, then the protection offered by breastfeeding could be argued to occur during the time period of greatest need.

The assessment of OM status at six years of age is a particularly relevant assessment in our cohort as this is the approximate age of school entry in this population. With the peak incidence of $\mathrm{AOM}$ and $\mathrm{OME}$ occurring between six to twelve months of age, later $\mathrm{OM}$ is generally indicative of chronic OME or recurrent AOM and its associated hearing loss. ${ }^{19}$ Age at school entry is a significant time-point in the development of a child, and the presence of hearing loss associated with $\mathrm{OM}$ at this time may negatively affect the child's educational achievement, through decreased teacher interaction and increased distractibility associated with the disease. ${ }^{20}$ 
Brennan-Jones et al.

The general health and immunological benefits of breastfeeding for children are widely recognised. ${ }^{21-25}$ However, its effect on the incidence of OM is still unclear. Rothstein and Bland ${ }^{26}$ were the first to report an increased incidence of OM in bottle-fed compared to breastfed children. They suggested that the transfer of Immunoglobulin A (IgA) in breast milk was protective against OM. Breast milk also contains host defence factors that inhibit Haemophilus influenzae, a major cause of $\mathrm{OM}$ and lower respiratory tract infections in childhood. ${ }^{27}$ Results from subsequent studies have varied, with some showing clear support for the positive benefits of breastfeeding ${ }^{1,28,29}$ whilst others have indicated no association..$^{30,31}$ There has also been the suggestion that it is the method of feeding (bottle versus breast) that creates an increased risk of OM, regardless of whether the bottled milk is formula or expressed breast milk..$^{21,32,33}$ The position of the infant during feeding (supine or semiupright) has also been proposed to contribute to an increased incidence of OM in infants, regardless of whether the infant was fed bottled formula milk, expressed breast milk from a bottle or predominantly breastfed. Tully et al. ${ }^{34}$ reported a $59.6 \%$ rate of abnormal tympanograms following supine bottle feeding compared to a $15.0 \%$ rate of abnormal tympanograms in infants fed in a semi-upright position, regardless of the contents of the bottle. They argued that supine bottle feeding results in aspiration of milk into the middle ear cavity resulting in blockages that may be linked to an increased incidence of OM. However, Rosenfeld ${ }^{35}$ has argued that whilst supine feeding may result in abnormal tympanograms of infants, these infants did not have a history of OM, and the effect of supine feeding on children prone to OM has not yet been established.

It has also been established that the mechanics of infant sucking for bottle-fed or mixed-fed babies are different to breast-fed babies, with fewer sucks and longer pauses observed for bottle-fed babies. ${ }^{36}$ Infant jaw movement facilitates opening and closing of the Eustachian tube $^{37,38}$ and the reduced sucking movements in bottle-fed infants may result in less 
Brennan-Jones et al.

ventilation of, or reduced clearance of fluid from, the middle ear. This reduced ventilation of the middle ear in bottle-fed infants may be another mechanism for increased risk of OM in this group.

A 2009 meta-analysis ${ }^{39}$ found a significant, protective association between exclusive breastfeeding for at least 4 months and risk of otitis media, compared to exclusive bottlefeeding (pooled OR $=0.50[95 \%$ CI $0.36,0.70]$ ). However, the majority of studies included in this meta-analysis followed infants for a relatively short period of time $\left(6,{ }^{40} 12^{41}\right.$ or $24^{42}$ months of age). Whilst there are limitations to our analysis, our findings support the results from this meta-analysis up to three years of age but do not extend the protective profile of predominant breastfeeding against OM for children beyond this point. Instead, our results indicate that other social, environmental and genetic factors may be stronger predictors of otitis media beyond three years of age. These factors could include exposure to potential bacterial or viral causes of OM through school-attendance, increased exposure to cigarette smoke, seasonal changes or other factors that may modify genetic risk. ${ }^{43}$ The findings at three years of age do support current $\mathrm{WHO}^{44}$ and $\mathrm{NHMRC}^{45}$ guidelines which recommend exclusive breastfeeding for at least six months, with the introduction of solid foods from 6 months ${ }^{44}$ or between $4-7$ months ${ }^{45}$ of age.

A number of potential mechanisms for the protective effect of breastfeeding on OM in early childhood exist, including immunological, ${ }^{27}$ feeding angle ${ }^{34}$ and the mechanical action ${ }^{36}$ hypotheses. However, it is possible that as children become older they become exposed to greater environmental risk factors that exceed the protective benefits provided by breastfeeding. Day care, for instance, was included in analyses as a covariate in our study and was significant across three of the multivariate analyses (Tables 3-5), and approaching significance in the fourth (Table $6, p=0.06$ ). 
Brennan-Jones et al.

Limitations of our study include the absence of genetic risk factors as co-variates and crosssectional categorisation of $\mathrm{OM}$ at three and six years of age meaning that we could not distinguish between children who were suffering acute or chronic forms of OM. However, all forms of OM presenting with middle ear effusion may reduce hearing levels for at least one to four weeks at a time which could have a negative impact on educational or developmental outcomes. Furthermore, the two OM groups (parent-reported at three years and confirmed by tympanometry at six years) are not directly comparable, with the six year old group having a more sensitive and objective diagnostic measure. Ideally, continuous monitoring of children including confirmation of middle ear disease by patient history, tympanometry or pneumatic otoscopy and audiometry is required. However, the skills, equipment and expertise for this are often not available when aiming to examine OM as part of a large-scale, longitudinal, multidisciplinary population cohort, such as the present study. In such cases, parental-report measures are often recommended ${ }^{46}$ and continue to be used ${ }^{47}$ to identify a broad presentation of OM that may include children with a wide range in severity of symptoms. The sensitivity of parental-report OM has been estimated to be between $75-95 \%$, with a specificity of 65 $100 \%,{ }^{48}$ with parents more likely to underestimate the number of episodes if the child had $<6$ episodes and overestimate episodes if the child had $>6$ episodes. The addition of tympanometry at six years of age strengthens the methodology of OM diagnosis at this time point, but also reduces the comparability of the two groups.

Studies examining the relationship between breastfeeding and illnesses are also subject to possible limitation by misclassification of exposure and outcome by confounding. ${ }^{49}$ To correct for limitations, four methodological standards have been proposed by Bauchner et al. ${ }^{49}$ for breastfeeding studies to adhere to. These include avoidance of detection bias, clear definition of the outcome event, clear definition of breastfeeding, and adjustment for potential confounding variables. All four recommended standards have been met in our study, and the 
Brennan-Jones et al.

odds ratios exhibited an expected direction of effect, suggesting biological plausibility and specific effects of predominant breastfeeding at three years of age. However, this study has not examined the specific composition of breast milk, and future cohort studies should consider the impact of maternal diet and breast milk composition on risk of OM.

\section{CONCLUSION}

As a multi-factorial disease, the risk of OM must be considered in the context of a range of prenatal, postnatal, genetic, social and environmental factors that contribute to its prevalence, incidence and severity. ${ }^{19}$ However, whilst the complete mechanisms of action are not fully understood, our findings suggest that where possible, breastfeeding predominantly for at least six months offers a practical method of reducing the risk of OM in early childhood. Our results indicate that the protective effect of breastfeeding is most evident in the first three years of life. However, it is during this period of early childhood development when breastfeeding could offer significant protection in reducing the impact of OM on language development.

\section{ACKNOWLEDGEMENTS}

The Raine Study is funded by the Raine Medical Research Foundation, the National Health and Medical Research Council (NHMRC), The University of Western Australia, The UWA Faculty of Medicine, Dentistry and Health Sciences, Curtin University, Edith Cowan University, The Telethon Kids Institute and the Women's and Infant's Research Foundation. We are extremely grateful to all the participants and their families who took part in this study, Jenny Mountain (Raine Study Manager) and the whole Raine Study team, which includes 
Brennan-Jones et al.

data collectors, cohort managers, data managers, clerical staff, research scientists and volunteers. AJOW is funded by a Senior Research Fellowship from the NHMRC (\#1077966).

\section{REFERENCES}

1. Paradise JL, Rockette HE, Colborn DK, et al. Otitis media in 2253 Pittsburgh-area infants: Prevalence and risk factors during the first two years of life. Pediatrics 1997;99:318-33.

2. Finkelstein JA, Metlay JP, Davis RL, et al. Antimicrobial use in defined populations of infants and young children. Arch Pediatr Adolesc Med 2000;154:395-400.

3. Vlastarakos P, Nikolopoulos T, Korres S, et al. Grommets in otitis media with effusion: the most frequent operation in children. But is it associated with significant complications? Eur J Pediatr 2007;166:385-91.

4. van Zon A, van der Heijden GJ, van Dongen TM, et al. Antibiotics for otitis media with effusion in children. Cochrane Database of Syst Rev 2012;9:CD009163.

5. Van Zon A, Van der Heijden GJ, Van Dongen TM, et al. Antibiotics for otitis media with effusion in children. Clin Otolaryngol 2013;38:54-5.

6. Rovers MM. The burden of otitis media. Vaccine 2008;26:G2-G4.

7. Morris PS, Leach AJ. Managing otitis media: An evidence-based approach. Australian Prescriber 2009;32:155-9.

8. Yoshinaga-Itano C, Sedey AL, Coulter DK, et al. Language of early- and lateridentified children with hearing loss. Pediatrics 1998;102:1161-71.

9. White J, Brennan-Jones CG. Auditory-verbal therapy: Improving the evidence-base. Deaf Ed Intl 2014;16:125-8. 
Brennan-Jones et al.

10. Brennan-Jones CG, White J, Rush RW, et al. Auditory-verbal therapy for promoting spoken language development in children with permanent hearing impairments.

Cochrane Database of Syst Rev 2014;3:CD010100.

11. Williams CJ, Jacobs AM. The impact of otitis media on cognitive and educational outcomes. Med J Aust 2009;191:S69-72.

12. Bennett KE, Haggard MP. Behaviour and cognitive outcomes from middle ear disease. Arch Dis Child 1999;80:28-35.

13. Bennett KE, Haggard MP, Silva PA, et al. Behaviour and developmental effects of otitis media with effusion into the teens. Arch Dis Child 2001;85:91-5.

14. Newnham JP, Evans SF, Michael CA, et al. Effects of frequent ultrasound during pregnancy - a randomized controlled trial. Lancet 1993;342:887-91.

15. Brennan-Jones CG, Whitehouse AJ, Park J, et al. Prevalence and risk factors for parent-reported recurrent otitis media during early childhood in the Western Australian Pregnancy Cohort (Raine) Study. J Paediatr Child Health 2015;51:403409.

16. Rye MS, Warrington NM, Scaman ESH, et al. Genome-Wide Association Study to Identify the Genetic Determinants of Otitis Media Susceptibility in Childhood. PLOS ONE 2012;7:e48215.

17. Li J, Kendall GE, Henderson S, et al. Maternal psychosocial well-being in pregnancy and breastfeeding duration. Acta Padiatrica 2008;97:221-5.

18. Slee VN. The International Classification of Diseases: Ninth Revision (ICD-9). Ann Int Med 1978;88:424-6.

19. Monasta L, Ronfani L, Marchetti F, et al. Burden of disease caused by otitis media: Systematic review and global estimates. PLOS ONE 2012;7:e36226. 
Brennan-Jones et al.

20. Roberts JE, Burchinal MR, Campbell F. Otitis media in early childhood and patterns of intellectual development and later academic performance. J Pediatr Psych 1994;19:347-67.

21. Labbok MH, Clark D, Goldman AS. Breastfeeding: maintaining an irreplaceable immunological resource. Nat Rev Immunol 2004;4:565-72.

22. Chirico G, Marzollo R, Cortinovis S, et al. Antiinfective properties of human milk. $J$ Nutrition 2008;138:1801.

23. Oddy WH, Robinson M, Kendall GE, et al. Breastfeeding and early child development: a prospective cohort study. Acta Padiatrica 2011;100:992-9.

24. Sassen ML, van Aarem A, Grote JJ. Validity of tympanometry in the diagnosis of middle ear effusion. Clin Otolaryngol Allied Sci 1994;19:185-9.

25. Oddy W, Sly P, de Klerk NH, et al. Breastfeeding and respiratory morbidity in infancy: a birth cohort study. Arch Dis Child 2003;88:224-8.

26. Rothstein RL, Bland RD. Otitis media in infants. Pediatrics 1972;50:167-8.

27. Hokama T, Sakamoto R, Yara A, et al. Incidence of Haemophilus influenzae in the throats of healthy infants with different feeding methods. Pediatr Int 1999;41:277-80.

28. Macintyre EA, Karr CJ, Koehoorn M, et al. Otitis media incidence and risk factors in a population-based birth cohort. Paediatr Child Health 2010;15:437-42.

29. Engel J, Anteunis L, Volovics A, et al. Risk factors of otitis media with effusion during infancy. Int J Pediatr Otorhinolaryngol 1999;48:239-49.

30. Etzel RA, Pattishall EN, Haley NJ, et al. Passive smoking and middle ear effusion among children in day care. Pediatrics 1992;90:228-32.

31. Rowe-Jones JM, Brockbank MJ. Parental smoking and persistent otitis media with effusion in children. Int J Pediatr Otorhinolaryngol 1992;24:19-24. 
Brennan-Jones et al.

32. Abrahams SW, Labbok MH. Breastfeeding and otitis media: a review of recent evidence. Curr All Asthma Rep 2011;11:508-12.

33. Brown CE, Magnuson B. On the physics of the infant feeding bottle and middle ear sequela: ear disease in infants can be associated with bottle feeding. Int J Pediatr Otorhinolaryngol 2000;54:13-20.

34. Tully SB, Bar-Haim Y, Bradley RL. Abnormal tympanography after supine bottle feeding. J Pediatr 1995;126:S105-11.

35. Rosenfeld RM. Clinical pathway for acute otitis media. In: Rosenfeld RM, Bluestone, C.D., ed. Evidence-based Otitis Media 2nd Ed. Ontario: BC Decker; 2003:280-302.

36. Moral A, Bolibar I, Seguranyes G, et al. Mechanics of sucking: comparison between bottle feeding and breastfeeding. BMC Pediatr 2010;10:6.

37. Bluestone CD. Impact of evolution on the eustachian tube. Laryngoscope 2008;118:522-7.

38. Bluestone CD, Doyle WJ. Anatomy and physiology of eustachian tube and middle ear related to otitis media. J Allergy Clin Immunol 1988;81:997-1003.

39. Ip S, Chung M, Raman G, et al. A summary of the Agency for Healthcare Research and Quality's evidence report on breastfeeding in developed countries. Breastfeed Med 2009;4 Suppl 1:S17-30.

40. Scariati PD, Grummer-Strawn LM, Fein SB. A longitudinal analysis of infant morbidity and the extent of breastfeeding in the United States. Pediatrics 1997;99(6):E5.

41. Duncan B, Ey J, Holberg CJ, et al. Exclusive breast-feeding for at least 4 months protects against otitis media. Pediatrics 1993;91:867-72. 
Brennan-Jones et al.

42. Duffy LC, Faden H, Wasielewski R, et al. Exclusive breastfeeding protects against bacterial colonization and day care exposure to otitis media. Pediatrics 1997;100(4):E7.

43. Massa HM, Cripps AW, Lehmann D. Otitis media: viruses, bacteria, biofilms and vaccines. Med J Aust 2009;191:S44-9.

44. WHO. Global strategy for infant and young child feeding. Geneva: World Health Organisation; 2003.

45. NHMRC. Eat for Health: Australian Dietary Guidelines. Canberra: National Health and Medical Research Council; 2013.

46. Vernacchio L, Vezina RM, Ozonoff A, Mitchell AA. Validity of parental reporting of recent episodes of acute otitis media: a Slone Center Office-Based Research (SCOR) Network study. The Journal of the American Board of Family Medicine, 2007, 20(2), 160-63.

47. Walsh P, Veith T, Rodriguez C, et al. Using a pacifier to decrease sudden infant death syndrome: An emergency department educational intervention. PeerJ, 2014; 2(e309).

48. Daly KA, Lindgren B, Giebink GS. Validity of parental report of a child's medical history in otitis media research. American Journal of Epidemiology, 1994, 139(11): 1116-21.

49. Bauchner H, Leventhal JM, Shapiro ED. Studies of breast-feeding and infections. How good is the evidence? JAMA 1986;256:887-92. 